\title{
Grief and the Counseling Process
}

\author{
Koutsompou Violetta-Irene (M.A)

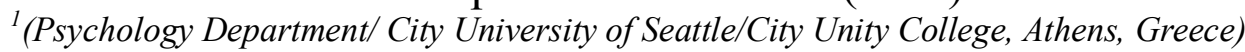

\begin{abstract}
Loss is an inevitable experience that all people will deal sometime in their lives. Loss is linked with death (death of a partner, loss of a child, losing a parent, losing a pet, losing a friend), but loss can also refer to the loss of a job, a divorce, loss of health, loss of friendship, loss of freedom. It applies in everything that someone had and it is taken away. Loss is accompanied by grief, which is the emotional response to loss. Depending on the personality and the nature of the loss each person experiences, there are several stages in the grieving process that all individuals must go through in order to recover, adapt to the new facts and continue their lives. The effects of bereavement but also the way counseling is helping through this process will be presented in this article.
\end{abstract}

Keywords: grief, counseling, loss, stages, reorganization.

\section{INTRODUCTION}

Each man is scared of death in his own unique way. For some, it looks like a page out of a novel, a page that once read, is not coming back. The experiences of a life lived on a daily basis are not coming back either, nothing is repeated anymore. So many people are haunted by terrifying thoughts in relation to their own death or the death of their loved ones. Each and every one of us, without exception, has had some sort of contact with death in our daily life; we have lost loved ones, or people familiar to us. Come to you think of it, even at the time of surgery we are in contact with a form of death (inaction), and when we sleep it is the same after all it is no coincidence that in ancient Greek mythology Death and Sleep were twins. Bereavement is the situation in loss of a loved one that manifests itself psychologically and physically even harmful to health symptoms. This article's main purpose is to inform you about the major theories of grief and the use of counseling process in this difficult time in life, in a more poetic, friendly approach and it attempts to show ways through which a person can transform this traumatic experience into a useful mature knowledge of life and self.

\section{THEORIES OF GRIEF}

Grief is the complex emotional response to bereavement. A number of people have sought theoretical explanations of grief while others have attempted to produce a model of grief by describing and categorizing the responses to loss. The physiological procedure model involved in recovery is known as mourning; it is the process that can be helped by people who will listen and understand in a sustained way (Feltham \& Horton, 2006). The major theories of grief seek to enlighten the basis of grief. Stress theory (Cannon, 1929) sees the response to bereavement as one example of the complex physiological and psychological responses of animals in danger. These responses were vital when early humans were hunter-gatherers living in a hostile world of unexpected dangers and predators. To survive such circumstances the response was fright, followed by fight and flight (Cannon, 1929). Nowadays, human beings still respond both physiologically and psychologically when fight and flight are not appropriate responses. The stress theory was elaborated further by Caplan (1964) who observed that people respond less severely if they have some preparatory knowledge of how to deal with a crisis and the effects of trauma, and that survivors are helped significantly by the support of others who have also been through the same or similar traumatic event. Even adding crisis theory to stress theory it is not sufficient to explain the response to loss in general. A psychoanalyst named Lindermann (1944), after observing the reaction of survivors from a fire in a night club where 500 people died, noticed that some people had delayed or distorted grief reaction. This led him to suggest that in these situations grief was being repressed and this was causing the delayed response. Therefore, repression was added to the theories to explain grief. Bowlby (1979) along with his colleagues developed a theory to explain the immediate reaction to separation and loss. Their observation of infants separated from their mothers led them to propose that the formation of an attachment between these two in the first year of life was critical for survival (Feltham \&Horton, 2006). If a baby is separated from its mother, its first urge is to cry until she returns. This is the basis of the instant reaction to separation at loss at any point of our lives. Extensive studies have shown four attachment patterns in infants; secure and insecure with three subcategories which are 1) avoidant, 2) ambivalent and 3) disorganized/disoriented. There are corresponding attachment patterns in adults. Secure and insecure with three subcategories which are dismissing, preoccupied and unsolved/disorganized; the quality of attachment whether it is secure or insecure, has a profound effect on 
the parenting styles of people in adulthood with attachment styles being transmitted from parent to child. The ability to manage loss is also influenced by attachment patterns. Those with insecure attachment are more likely to show prolonged and chronic grief when a relationship is lost. More recent research by psychoneurobiologists such as Eisenberg, Hobson, Shore and Trevarthen (Feltham \& Horton, 2006), has produced neurological evidence for the crucial role of attachment behavior and emotional communication in brain growth of the orbit frontal area of the brain and in emotional development. This is the socio-emotional part of the brain; the area responsible for empathy and attunement (Shore, 2001). What attachment theory does not do is attempt to explain the recovery from bereavement and the way in which some people change, develop a new identity and sometimes become mature as a result. This possible change is called the psycho-social transition by Parkes (1971) and is based on the work of Marris (1974). Bereavement challenges people's assumptions that have been made on the grounds of previous experience are no longer correct. Part of the grief work is coming to terms with a different relationship with the deceased, the world and oneself; in many ways, the work is learning about and coming to terms with a new "I" (Feltham \& Horton, 2006), of course more details about this procedure will be given in the following parts of this article.

\section{GRIEF AND COUNSELING}

\section{Overview of symptoms}

There are many different types of loss and mourning: divorce, separation, loss of a beloved animal, loss of business, loss of freedom, suicide, death of a parent, of a child, of a friend, of a brother, of a partner. Similarly with depression and lament - mourning and trauma share many behavioural similarities. Stroeve, Schut and Finkenauer (2001) make the following distinction: Trauma without lament: here, the person experiences the traumatic event in such a way that it triggers symptoms of post-traumatic stress. Other symptoms of depression and anxiety may lead to a misdiagnosis. In this case, the person experiences the classic symptoms of PTSD, but without lament. 1. Lament without trauma: here, the person experiences loss without any symptoms of stress. The third category is the traumatic grief where the person experiencing death so directly associated with the trauma, e.g. sudden and violent death.

\section{Normal mourning}

In literature it is often mentioned that there exists what we very simply referred to as normal mourning. According to Worden (2009) there are four general categories of symptoms

1. Emotions

2. Physical Symptoms

3. Perceptual Processes

4. Behaviours

The Emotions experienced within a normal spectrum are: sadness, anger, guilt, anxiety, loneliness, helplessness, shock, relief, fatigue, numbness. Depending on the type of loss, these feelings are common and are often visible by the people of their immediate environment. The physical symptoms they exhibit are: pain in the chest, neck discomfort, pain and discomfort in the stomach, dry mouth, lack of energy, muscle weakness, hypersensitivity to sounds, difficulty breathing. Similarly, we have problems in their perceptual ability: disbelief, confusion, and intense preoccupation, difficulty in understanding a sense of time and space and illusions. Finally the most important and severe symptoms occur in one's behaviour : sleep disturbances, appetite disorders, ambivalence, social exclusion, dreams about the deceased, avoidance of ant discussions about the deceased, hyperactivity, crying, visiting places that remind him/her of the deceased, keeping objects of the deceased etc. All the above, are some of the most common symptoms experienced by those who experience a loss or mourning. It does not necessarily mean that all these symptoms are there, or that anyone experiencing all of them is worse than someone else. This classification helps us to understand what is happening and whether this is normal. Often, mourning is confused with depression and although there are many similarities, we can also identify several differences. Freud (1917-1957) in his article "Mourning and Melancholia" describes depression or melancholia as he called it, as the pathological form of mourning with one important distinction: anger and ambivalence towards the loved one returns to the individual. It is true that grief can evolve into depression. While depression and grief have as common symptoms sleep disturbances, appetite disturbances and intense grief, the patient does not exhibit any lack of self-esteem which is common in clinical depression. Moreover, if they experience guilt this is not due to lack of self-esteem but a feeling of guilt and responsibility for a specific aspect of death. 


\section{Stages of mourning}

Attempting to understand the process of managing the mourning, one should understand the different stages experienced by each individual. Depending on the approach we have 2, 5, 9, or 12 stages. The first attempt was made by Elizabeth Kübler-Ross (1969) who studied not only those mourning but those who knew they were suffering from a disease and they would eventually die. According to her study, the stages are: 1. Shock and Denial: The initial reaction is shock, followed by a refusal - this is wrong. Some people never go beyond this stage and may require many opinions in order to accept it.

2. Anger: Patients become angry and wonder "Why me ". Anger can be turned against friends, relatives, doctors, God, etc.

3. Bargaining: at this stage one seeks a reward, e.g. I will do this so I'll be healed.

4. Depression: In this phase, the patient exhibits depressive symptoms: abandonment, hopelessness, sleep disturbances, suicidal thoughts.

5. Acceptance: the person realizes that death is inevitable and accepts its universality.

In these 5 stages described by Kubler-Ross, many research papers and studies are based. Parkes (1972)

describes four steps-phases: 1. Numbness, 2. Desire, 3. Despair and Disorganization 4. Reorganization

Correspondingly, Sanders (1989) identifies five stages 1. Shock, 2. Acknowledgement of loss, 3. Preservation of withdrawal, 4. Healing 5. Renewal. Regardless of how many and which stages anyone is experiencing, what is important is to be able to continue to live with the loss. In none of the above models, does it appear that one returns to a previous state; we simply learn to live with the new situation either through acceptance, reorganization and renewal.

\section{Dealing with Mourning}

What interests us the most, is to see how we can evaluate the different stages, levels, parts of mourning and help the individual go from one stage to the next and become and more functional. These steps are called tasks- objectives of mourning (Worden, 2009)

Objective 1: To accept the reality of loss

Even when death is expected, there is always the feeling that it is not real, that it did not happen. We would argue that their first Objective would be to face reality: the person is dead and will never come back. At this stage, problems that might arise from the beginning, when they call for the deceased, or think they see the person, if they deny the incident, when they do not touch the deceased's objects and try to be ready when he/she returns, or even say " we weren't that close " or by throwing away all of the dead's personal objects. They often exhibit selective memory loss, they turn to religion with great dedication. Accepting reality includes not only the acceptance of information but both the spiritual and the emotional acceptance.

Objective 2: To process the pain of mourning.

According to Parkes (1972), it is important for the mourner to experience the pain of grief - of mourning - in order to move on At this stage, one needs to manage anxiety, stress, guilt, depression and loneliness. The denial of this second stage leads to loss of feeling, of emotions. They are cut off from their own emotions, they deny the pain, they avoid painful thoughts, and they abuse alcohol and substances, triggering other pleasant thoughts (so that they may avoid any discomfort).

Objective 3: To adapt to a world without the deceased.

At this stage, one should make some external, internal, and spiritual adjustments. External adjustments would include a new environment, other people, raising their children alone, being in an empty house, managing their own finances, losing a sexual partner, learning new roles usually played by the deceased. To these, internal changes are added such as self-determination, self-esteem, self-effectiveness, mainly feeling whole by themselves and not half as part of a duo. Finally, there are spiritual adjustments included which may falter like philosophy and religion concerning life and the world in general.

Objective 4: To find a continuous connection with the deceased as a means to start a new life.

To talk, to think, to dream and to feel that the one who died is watching them, does not help them move on with their lives. Volkan (1985) mentions that mourning ends when the mourner does not so much need to reactivate the dead's representation in the flow of everyday life. The role of the therapist is not to help the mourner abandon the relationship with the deceased, but to help him find a suitable place in his emotional life - such a place that will help him to continue living effectively in the world. This is the most difficult stage. According to Worden the mediators of mourning play an important role; the reasons, that is, which affect how deep is the mourning and how long it will last. These factors are seven:

1. Who was the person who died: partner, child, parent, sibling, relative, friend, lover, grandfather?

2. The nature of the relationship: the intensity of the relationship, the security of the relationship, its ambivalence, the conflicts and the dependency.

3. How did the person die: natural causes, an accident, a suicide, a murder, an illness

4. Previous experiences: it is important to know how someone reacted to a previous death, their medical history 
and the way family deals with death.

5. Personality: age and sex, the way one deals with problems, their way of commitment, their self-esteem and self-efficacy and their values; they affect how much and how will the individual mourn.

6. Social factors: if they have people in their environment who support them, if they have a social role or involvement with religious duties.

7. Simultaneous stress factors: If parallel to the loss, they have experienced any other stressors e.g. job loss, financial problems, etc. All these factors affect the intensity and duration of the symptoms of loss.

\section{Therapy for Mourning}

Is not a given that someone experiencing grief or one of the other forms of loss seeks help from a specialist. In most cases, people let time heal the wounds. But there are cases where the contribution of a specialist is important: when pain is multidimensional when there is delayed mourning, when excessive reactions are observed and when there are any physical or behavioural signs that outshine grief (Worden, 2009). In case of chronic grief there is a differentiation between what our culture considers a normal period to grieve over someone, and what is actually happening and, in this case, it is significant (Stroebe, 2001). Treatment is focused on "solving the stages that were not completed and on helping the person move on". Accordingly, in delayed mourning which occurs mainly because there has been no social support, or because the need to appear strong or support another family member, or experience intense discomfort due to the consecutive losses; in this case too we need therapy, in order for the individual to experience all stages of loss and lead a more functional life. The most important part in therapy is for the patient to not feel worse than before, e.g. if he feels unexpressed anger and this is evident in treatment, the patient cannot be left with the guilt of anger (Worden, 2009).Treatment procedures of mourning are complex. Depending on the approach and the theoretical background of each therapist, according to the kind of loss and mainly according to the patient, different approaches are applied. But they all have some common principles which we will mention below.

Principle 1. We help the survivor to acknowledge the loss. The full knowledge of what has happened is the first step and it is achieved through discussion (when, how, who told you where were you when you found out, how was the funeral, what followed, etc.).

Principle 2: We help the survivor to recognize and experience one's emotions. Feelings of pain are unpleasant and not easily discussed. Anger, guilt, anxiety, helplessness, loneliness are some of them. We will analyze them and observe how they are expressed in everyday life. They may not be verbally expressed but they are experienced through physical symptoms or suicidal thoughts. How do you feel, what makes you think ... what did not, what else could you do, you're angry that he died, what do you miss, what frustrated you, what is wrong etc. these are some of the interventions that we can do to help them discuss and acknowledge their feelings.

Principle 3: How one's life has been adjusted after the loss. To adapt to a new routine is equally difficult in accepting reality. With the "solution focused" approach which implies it is best to focus on specific problems and to focus on their solution, we provide a way out to the survivor who thinks his world around him is destroyed. In addition to daily habits, food, shopping, financial support, friendship, companionship, sexual partner, they lose the flow of everyday life and they need to redefine it . They would be rushing, if they decided to do another change, like selling their house, change their jobs, move, etc. because very often they repent it.

Principle 4: Searching for the meaning of loss. The way everyone finds to "explain" loss, what they learned from it, what does this mean for me and my life is connected to culture, religion, and is usually way more silent than the process itself. (Schwartberg and Halgin, 1991). Interventions such as: why do you think this happened, why this has happened to me, how I've changed after that; they lead to this very realization.

Principle 5: Organization of emotions concerning loss. The psychologist can help the survivor to seek a new place in his life for the individual who has been lost, a place that will help him go ahead and make new relationships. This, however, does not mean that he will dishonor the memory of the deceased, "whoever is gone cannot be replaced ... and it is normal to want to move on. »On the other hand, if the "substitution," is done very fast, i.e., a second marriage, this often leads to subsequent loss....

Principle 6: Give mourning time.

If we are talking about time frames, they are hard to define. Others say six months. If appearances and behaviors are identical and have the same intensity even after six months then the intervention of a specialist is necessary. In the new DSM-V, mourning will be added and timeframes will be set. There are also the cases where mourning cannot be experienced... which means that the person remains stuck on a particular stage of the process and cannot move on; this often proves his life becomes dysfunctional. Then, we deal with chronic grief, delayed grief reactions, overreactions to mourning or covert reactions to mourning.

How do we actually proceed to diagnosis? There are some elements which may aid in making a diagnosis for one of the above mentioned categories.

1. Not talking about the deceased without experiencing tension 
2. Even the slightest mention causes a strong reaction in the mourning process

3. Death scenes are described within our discussion.

4. Reluctance to remove objects that belonged to the deceased

5. They adopt physical symptoms, similar with those of the deceased.

6. They make radical changes in their life, pushing away friends and relatives

7. They have a history of depression, guilt and low self esteem

8. There is an obsession in mimicking behaviours of the deceased.

9. A huge grief which comes up in particular moments in time.

10. Phobias about death and sickness

11. Avoids visiting the grave or discuss it. (Worder, 2010)

This is information which can be assessed in order to trace the difficulty one has to experience loss. Whatever the issue might be, theoretically, it is when you are called to apply the theory in real life, that things get tough, and every story is different from the other, every pain is different from the other and every individual experiences loss in one's unique way. All the information provided here, are important tools that any therapist should use in order to better handle/deal with a case of loss. What should also be pointed out is that a case cannot be taken by us, if we cannot handle it, a case that causes grief, or one which reminds us of similar ones from our own life. In any case, the role of our therapist, along with the role of the supervisor is very important! Our Objective would be to render understandable that the process of grieving is a natural one; it has multiple consequences which concern not only the one going through this process (partner, child, parent) but one's more extended frame. What's more important, everyone can be helped in living with their grief and not by simply overcoming.

\section{LOSS AS AN AWAKENING PROCESS OF LIFE AND MATURITY}

In fact, if you turn to the past and study past cultures and peoples, it is impressive to see the fact that death has always been something man despised, and probably it will remain so forever. Within our subconscious, death is never possible in reference to ourselves. It's inconceivable to imagine a real end of our own lives, and if this life must end, the end is attributed to some external influence (Kubler-Ross, 1969). Perhaps, this knowledge can help us understand many old customs and rituals that lasted for many centuries; their purpose was to reduce the anger of the gods or the people depending on the situation, thereby reducing the expected punishment. The ash, the torn clothes, the shroud, the mourners- all within the boundaries of seeking sympathy for those who mourn; they are expressions of sadness, grief and shame. If someone hurts, pounding his chest, pulls his hair, refuses to eat- this is an attempt at self-punishment to avoid or undermine the anticipated retribution for the guilt he feels for the death of his loved ones. For example, the ancient Jews considered the body of the deceased as dirty therefore it should not be touched. The first American Indians spoke of evil spirits, throwing arrows into the air to cast them away. Many other cultures used rituals that took care of the "evil dead". All are rooted in the feelings of anger always lying within men. We should not forget that the process of grief caused by loss always includes some properties of wrath. The tradition of a grave stele may relate to this desire to keep evil spirits down into the earth. Even the stones that many mourners lay, these examples indicate that any anxiety about death remains the same over time; always a terrible, horrible event for humans. However, what can be changed is not that the primary fear, which is associated with the existence of man, but the way by which people face death.

Awareness of death can function and serve as an awakening experience in every person's life, as a process of maturity and deep reflection. It can also serve as a means for change in the way a person is experiencing life, helping to create a new value system. Let's not forget that the most famous literary hero, Ebenezer Scrooge, from Charles Dickens' A Christmas Carol, undergoes a miraculous transformation, and towards the end the reader wonders if it is the same hero he reads about, from the beginning of the story. What influenced Scrooge change was not the Christmas atmosphere or even the poverty of the era, but the Spirit who shows him his future, a future that includes death. Scrooge, therefore, is confronted with his very own death, with the indifference of the people who knew him, watching his own grave, and so through this process he is transformed into a new man; through this process, from an evil and stingy man, he becomes a sweet, compassionate person. What one grasps is that through grief, fear of death and loss, a man is likely to "negotiate" his very experiences and begin to assess the facts of his life, in a new light.

In order to understand how important the notion of loss in our life is, we will explore some ways in which the word "mourning" is used and the notions it bears in some languages. The French, for example, have a single term for mourning, the term «deuil», to signify the loss of a beloved person, and also the psychological condition caused because of this loss. The English language, in contrast, uses, according to the condition, three different nouns: «bereavement», «grief» and «mourning». Specifically: the word «bereavement» denotes the objective loss, the deprivation, ie, the very state of mourning, and by extension «bereaved people» can be 
depicted as "mourners".The noun «grief» refers directly to unhappiness, sorrow, grief, pain and corresponds etymologically to the French word «douleur», derived from the Latin «dol», the verb dolere », which means suffering. Finally, the noun «mourning» refers more to the social dimension of mourning and is used mostly to express the grieving process, the participation in mourning (Bacque, 1997). The expression "I experience my grief" that has prevailed in recent years, corresponding to the painful internal process which describes the acceptance of loss and the irreversibility of it.

From these observations one may realize that, by the meanings given to words, the process of mourning in Western societies is a such a crucial concept; it requires time and energy for the reconstruction of the individual. All of the above are very important observations. However, the question one may ultimately pose is this: "What is mourning?" "What does grieving mean?" and "What does facing a loss mean?" Regarding the specific quests, Antoine de Saint-Exupery writes in The Little Prince:

[...] And the little prince said: "Good ... That's all." He still wobbled a bit. Then he got up and took a step ... he did not yell. He fell gently as a tree, falling in the sand. Not a single sound was heard. And now surely it has already been six years. This is comforting to me, because I know that has actually returned to his planet, but at dawn I did not find his body. Since then, at night I sit and I listen to the stars ... it's as if I listen to a thousand, a million little bells...Through this brief excerpt, one can understand how loss is experienced, how sweet and beautiful is the way it is described and in such a tender way the author gives the definition of mourning, yet also the emotions that it entails, like those of pain and sorrow. Grief, then, is the painful, normal process of a loss which aims to adjust and harmonize the internal and external condition of a man, in light of a new reality (Bucay, 2010). In this context, "processing mourning" means that I come in contact with the void left by the loss of the person which no longer exists; I evaluate its significance and I any surmount pain and despair coming from that absence.

The process of mourning, and by extension all forms of loss in life, is a very important step towards the inner world of the individual, since it is yet another stepping stone towards awareness and self-realization. Referring to Freudian psychoanalysis, we can see it examines life as a constant struggle between two primordial, instinctive forces, Love and Death, with the desire for life is trying to impose on the unconscious desires of death. Also, motivated by Karl Abraham, who had worked on the similarity between mourning and melancholia, since 1911 Freud initiated a true scientific debate about mourning. Specifically, in 1917, he published a critical article entitled "Mourning and Melancholia"; the importance of which lies in the fact that grief is displayed as a normal feeling. For Freud, mourning is the reaction to the loss of a loved one or an abstract concept which replaces it, such as homeland, freedom, etc. This is a reaction to a real loss, which in the quest for a finding a tangible solution lures the psyche of the individual into a process of acceptance, the socalled "process of mourning» (Bacque, 1997).

Many analysts were inspired by Freud to deepen their research on this issue, for example, Melanie Klein (1940), which considers that the model for the process of mourning is the "depressive phase" for all, which coincides with the weaning child phase. When the cabbalistic relationship with her mother starts to ease off and the outside world becomes more important, the infant is experiencing a first demystification of the mother-child relationship - a model for all future disappointments. The mother does not live 1 exclusively for this anymore, and both of them are no longer alone in the world. The child, at this stage, develops feelings and fantasies of a hostile nature. Soon, however, the grief associated with the deprivation of the mother outweighs all other feelings. Therefore, the infant internalizes the mother's image, smell and above all her love, so that her frequent absences can be acceptable. This emotional process essentially creates the integration capacity for every mourning the child will experience in the future. Besides, all changes involve loss, as all losses require change as hard as that sounds. Where are the losses in daily life? Who are the biggest catalysts for the awakening experiences; what are the urgent events of life?

So many are the examples relating to this field, such as mourning the loss of a loved one, the loss of one's health due to serious illness, loss of a pet, the interruption of a very close relationship (eg divorce , friendship), a major milestone of life-for example birthday in old age (beginning of the third age, old age) - a cataclysmic trauma (eg, robbery, fire, rape), the departure of children from home and the syndrome of the empty nest, a career change or a job loss, retirement, moving of any kind; dreams also function as an awakening experience, which carry messages from our deepest self (Yalom, 2008). The serious losses with which life is filled, pose constant challenges that must be challenged again and again, passing through various stages in the journey called life. Worden (1996) argues that the child or the adult who is grieving, faces four "tasks" which may, to some extent, be resolved as part of the total adjustment of the individual to loss. These tasks do not occur in a fixed order and the person may be able to revisit each of them from time to time. These tasks include the following: (a) accepting the reality of loss, (b) experiencing the pain of loss, (c) adaptation to an environment from which the deceased is missing and (d) repositioning the deceased into the mourner's life and finding ways to keep his memory alive. 
Rando's outlook (1993) is relatively more complex and outlines six "processes" of death, each of which includes a variety of sub-processes. The main processes include: (a) acknowledgement of loss, (b) reaction to separation, (c) memory of the deceased and the relationship with the bereaved, (d) cutting off from old ties with the deceased and the old world of beliefs, (e) readjustment of the bereaved in order to continue into the new world without forgetting the old one and (f) reinvesting in new relationships and goals. Although there is a differentiation in the above mentioned theories, both deal with the acceptance and reintegration of the bereaved into the new realities of his life and the wider social context. The loss is associated with life, with oneself and above all with human existence, it irritates sensitive strings and raises questions quite tantalizingly, which are left unanswered: "Why?" "How?" "What happens after this?"... A person's attempt to understand life and death reminds us of Sisyphus, who was condemned by the gods to endlessly push a rock up to the top of a mountain from where the stone tumbled over, due to its own weight. Sisyphus, is the hero who shows how absurd life is and the true nature of humans, he is the one who brings the stone up the mountain, watching it fall over again; this whole process is constantly repeated in life, each of us may experience it, and there lies the significance of this myth. By Camus (1942) writes that: "There is no sun without shadow, and we must know the night", so every loss is the shadow of the sun, of life, which should be processed by humans so as to overcome it and create a new self.

That's life, a circle which although it seems to be running out and something within us is completed, one can suddenly come face to face with a loss. And everything is reversed and man is back at the beginning of the road, carrying a suitcase full of emotions, behaviors, situations, experiences, life philosophy, all these and many more which are questioned. So, instead of completing a circle, we are again at the beginning, we begin the learning process again. The experience of a significant loss in the life of an individual does not only deprive him of his beloved people, but more often it undermines the value system one has formed about life, and his beliefs in general. People, therefore, enter into a process of questioning: they question life, faith (especially in cases of parents who grieve the death of their child), the sense of God's justice or even fate. So there is a reversal, and this implies consequences in the behavior of the individual, his own views and values, which require great effort, take a long time and last a lot longer after the assimilation of the very reality of death. It occurs, therefore, the review of all the convictions of the individual in relation to himself and his life. The difference of each person is the main factor that will dictate how he will integrate loss into his life. What matters is that through this tough test and the awareness of human mortality, one can revise priorities, his belief system and to also ensure that spending time dedicated to people and goals is really important.

By integrating the traumatic experience into the revised world of beliefs and by giving it a personal meaning, tragedy can be transformed and experience can make a person sadder but also wiser. Janoff-Bulman and his colleagues (Warren, 1989) reflect the views of existential philosophers and psychotherapists, who argue that the all-out, primordial encounter with the reality of the inescapable human mortality is a prerequisite to live more authentically in the present (Warren, 1989). The matter of rebuilding the world occupies a special place in the model of meaning reconstruction of the individual. When a loved one is gone, the mourner not only loses the one who leaves forever, but also a part of himself that lived with him, an important piece of the past, a part of his own life. What is important is not to steer away from his beloved who "left", but to "embrace" the memories and create a symbolic link, a bond which can be confirmed through a favorite "transitional object" such as, for example, a t-shirt (Klass, 1997)....

All forms of loss destabilize the inner self of the individual, while requiring work in order to create a new present, which will provide a basis for a future life. Since the person has experienced a significant loss, he cannot go back to his "old self", because now he is experiencing significant feelings and upheavals in his life. Also, it requires effort to build a new identity based on this new experience, while this new approach of oneself must be of continuity of the old one. Of course, this whole process takes some great personal effort, work and time. Maintaining connectivity with a vital relationship of the past can give the person a sense of continuity in life, as the survivor seeks a meaningful future (Klass, 1997)....Tom Attig (1996) understands the concept of the bereaved's identity more as a social phenomenon; he likens it to a web which connects us with people in which invest our love and concern. Consequently, loss evokes a cut in this web, thus creating the need for a rediscovery of ourselves, and a revision of all the views we have had of life so far.

\section{Conclusion}

As a conclusion, we could say that loss teaches people to revise their personal philosophy, challenges them to broaden their identity, to look at loss directly, to grieve, to accept what cannot be changed or adapted, to survive and mature.... The loss and the deep pain the mourner bears is a parallel universe that, when crossed with the self of the person through the experience of a large or a small death it enhances how valuable are the ties that sustain the individual, and how fragile the very substance of life, which reminds him of the deeper and supreme issues of his existence. Growing up, we discover that our past serves as a close companion; there is a cycle which is completed where difficult aspects and parts of one 'soul are evened out, of one's personal history 
and the strength to embrace all which has made him what he has become, is found. All the painful experiences and everything he has ended up being. It is a very important lesson, an overwhelming journey-this is life and this, for that matter is loss.

\section{Books}

[1]. Attig, Tom (1996), How we grieve: Relearning the world, New York: Oxford University Press.

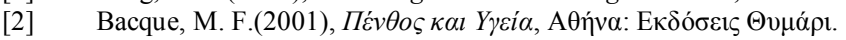

[3]. Bowlby, J. (1979) The Making and Breaking of Affectional Bonds. London: Tavistock.

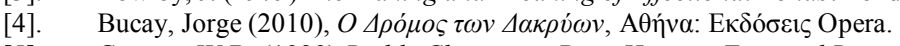

[5]. Cannon, W.B. (1929) Bodily Changes in Pain, Hunger, Fear and Rage. London: Appleton

[6]. Caplan, G. (1964) Principles of Preventive Psychiatry. New York: Basic Books

[7]. Feltham, C. and Horton, I. (2006). The Sage Handbook of Counseling and Psychotherapy. London: Sage Publications.

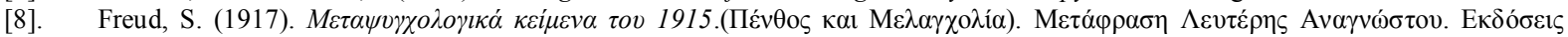
Елі́коuроৎ (2005).

[9]. Klass, D., Silverman, P.R. and Nickman, S. (eds) (1996) Continuing Bonds: New Understandings of Grief. London: Taylor \& Francis.

[10]. Klass, D.(1997), The deceased child in the psychic and social worlds of bereaved parents during the resolution of grief, Death Studies, 21, 147-176.

[11]. Klass, D., Silverman, P.R. and Nickman, S. (eds) (1996) Continuing Bonds: New Understandings of Grief. London: Taylor \& Francis.

[12]. Kubler-Ross, Elizabeth (1969), On Death and Dying. New York: Macmillan.

[13]. Kubler-Ross, E.(1975). Death and the final stage of growth. Englewood Cliffs: Prentice Hall, Inc.

[14]. Lendrum, S. And Syme, G. (2004) Gift of Tears. London: Routledge.

[15]. Lindermann, E. (1944) The symptomatology and management of acute grief. American Journal of Psychiatry, 101: 141.

[16]. Marris, P. (1974) Loss and Change. London: Routledge and Kegan Paul.

[17]. Parkes, C.M. (1971) Psychosocial transitions: a field for study. Social Sciences and Medicine, 5: 101.

[18]. Parkes, C.M. (1972). Bereavement: Studies of Grief in Adult Life. London and New York. (Penguin edn. 1975).

[19]. Parkes, C.M. and Brown, R.J. (1972). Health after bereavement: a controlled study of young Boston widows and widowers. Psychosomatic Medicine, 34, 466-491.

[20]. Rando (1993), Treatment of complicated mourning, Champaign, IL: Research Press.

[21]. Sanders, C. (1989) Grief: the mourning after. New York: Wiley

[22]. Schwartberg, S. \& Halgin, R., (1991). Treating grieving clients: the importance of cognitive change. Professional Psychology, 22, 240-246.

[23]. Stroebe, M.S, Schut, H. \& Finkernauer, C. (2001) The traumatixationof grief: A conceptual framework for understanding the trauma bereavement interface. Israel Journal of Psychoatry and Related Sciences, 38, 185-201.

[24]. Warren, W.G. (1989), Death education and research: Critical Perspectives, New York: Hawarth.

[25]. Worden (1996), Children and grief, New York: Guilford.

[26]. Worden, W. J. (200) Grief counseling and grief therapy: A handbook for the mental health practitioner. New York: Springer Publishing Company

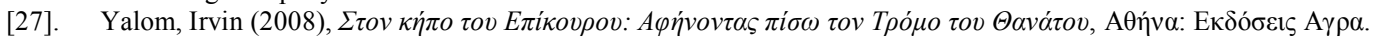

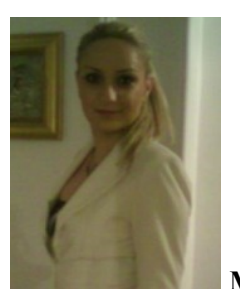

Ms Koutsompou Violetta-Irene was born and raised in Polidrosos, a village at the outskirts of Mountain Parnassos, in Greece. She holds a BA in English and Psychology (2007) from the State University of New York, USA, a Masters degree in English and Comparative Literature (2009) from the University of Indianapolis, USA, an accredited Certificate in TEFL from the Hellenic American Union (2007) and a Diploma in Counseling Psychology (2013) from City Unity College, Athens, Greece, She is completing an MSc in Psychology with the University of East London, UK (2013-14) and she is working towards her thesis concerning postnatal depression on an MA in Counseling Psychology with the City University of Seattle, USA. Her areas of interest and concentration are psychology of child development, children's literature and its impact on the cognitive development, depression, grief and loss, stress management, second language acquisition, the use of literature in the language classroom and its benefits, postmodern literature, women's psychology and writings, book editing and writing. She has conducted research concerning second language acquisition and the young learners as well as grief, counseling and the grieving process in all aspects of life; she has participated as a co-author in a forthcoming book on grief and loss. She has presented her work in many Conferences in Greece and abroad. Ms Koutsompou worked in private language institutions since 2005; she was interested and worked with children with special learning difficulties such as dyslexia, as well as with children with behavioral problems in the language classroom.

Publications: Koutsompou Violetta-Irene, "Young Learners: How advantageous is the early start?" IOSR Journal Of Humanities And Social Science (IOSR-JHSS) Vol. 15, Issue 5 (Sep. - Oct. 2013), pp 27-37 Kotsopoulou Anastasia and Koutsompou Violetta-Irene, "The Grieving Process during the Economic Crisis in Greece", Journal of Economics, Business and Management vol. 2, no. 4, pp.313-317, 2014. 